\title{
Management of Infectious Processes of the Pleural Space: A Review
}

\author{
Ankur Girdhar, Adil Shujaat, and Abubakr Bajwa \\ Division of Pulmonary and Critical Care Medicine, UF College of Medicine at Jacksonville, 655, 8th Street west, \\ Jacksonville, FL 32209, USA \\ Correspondence should be addressed to Ankur Girdhar, ankurgirdhar@yahoo.com
}

Received 22 August 2011; Revised 12 December 2011; Accepted 17 December 2011

Academic Editor: Takashi Nakano

Copyright (c) 2012 Ankur Girdhar et al. This is an open access article distributed under the Creative Commons Attribution License, which permits unrestricted use, distribution, and reproduction in any medium, provided the original work is properly cited.

Pleural effusions can present in $40 \%$ of patients with pneumonia. Presence of an effusion can complicate the diagnosis as well as the management of infection in lungs and pleural space. There has been an increase in the morbidity and mortality associated with parapneumonic effusions and empyema. This calls for employment of advanced treatment modalities and development of a standardized protocol to manage pleural sepsis early. There has been an increased understanding about the indications and appropriate usage of procedural options at clinicians' disposal.

\section{Introduction}

Any effusion that occurs secondary to an infectious process in the lung parenchyma such as pneumonia or lung abscess is defined as a parapneumonic effusion. A complicated parapneumonic effusion requires an invasive procedure for resolution and usually a bacterial organism can be cultured from the pleural fluid [1]. When a parapneumonic effusion progresses to become frank pus, it is labeled as empyema. Parapneumonic effusion and empyema are both important medical conditions associated with significant morbidity and mortality.

Infection of the pleural space affects approximately 60,000 individuals in the USA annually and has approximately $15 \%$ mortality [2]. About $40 \%$ of all patients diagnosed with pneumonia have an associated pleural effusion, out of which only a few require active intervention for resolution [1, 3, 4]. Recent epidemiologic studies have indicated that the incidence of empyema has been increasing in the last two decades $[5,6]$.

In view of the increasing incidence and considerable mortality and morbidity associated with pleural infections, there is a need to utilize modern principles of empyema management that will promote early diagnosis and prompt pleural drainage. It has been observed that any delay in initiating effective drainage can result in prolonged hospital stay, requirement of an invasive procedure for drainage, and further increase in mortality and morbidity [1, 7-9] (Table 1).

\section{Pathophysiology of a Parapneumonic Effusion}

Any inflammation due to an infectious process in the lung parenchyma leads to disturbance in the delicate balance between formation of pleural fluid and its clearance resulting in accumulation of fluid in the pleural space. This pleural fluid initially can be sterile but if left untreated can progress to become an empyema. This progression occurs in three stages (Table 2) [10].

At the very beginning, inflammation due to pneumonia in the lung parenchyma increases vascular as well as visceral pleural membrane permeability by molecules like vascular endothelial growth factor (VEGF) and there is outpouring of inflammatory fluid in the pleural space [11]. This is known as the exudative phase. At this stage, the pleural fluid is nonviscous, free-flowing, and readily drained by thoracentesis or chest tube. During this stage, pleural fluid culture is negative for bacteria, fluid $\mathrm{pH}$ is $>7.20$, the glucose 
TABLE 1: Pleural infections staging and recommended drainage [7].

\begin{tabular}{|c|c|c|c|c|c|}
\hline Category & Pleural space anatomy & & Pleural fluid chemistry & Risk of poor outcome & Drainage \\
\hline 1 & $\begin{array}{l}\text { Minimal free-flowing effusion ( }<10 \mathrm{~mm} \text { on } \\
\text { lateral decubitus) }\end{array}$ & and & $\begin{array}{l}\text { Gram stain and culture results } \\
\text { unknown }\end{array}$ & Very low & No \\
\hline 2 & $\begin{array}{l}\text { Small to moderate free-flowing effusion } \\
(\geq 10 \mathrm{~mm} \text { and less than one half hemithorax) }\end{array}$ & and & Negative Gram stain and culture & Low & No \\
\hline 3 & $\begin{array}{l}\text { Large, free-flowing effusion ( } \geq \text { one half } \\
\text { hemithorax), loculated effusion, or effusion } \\
\text { with thickened parietal pleura }\end{array}$ & or & Positive Gram stain and/or culture & Moderate & Yes \\
\hline 4 & Empyema & & pus & High & Yes \\
\hline
\end{tabular}

TABle 2: Different stages in the evolution of an infected pleural effusion with associated pathological changes and pleural fluid findings.

\begin{tabular}{|c|c|c|}
\hline Phase & Pathology & Pleural fluid findings \\
\hline \multirow{4}{*}{ Exudative } & \multirow{4}{*}{$\begin{array}{l}\text { Increased } \\
\text { permeability of } \\
\text { vascular and visceral } \\
\text { pleural membranes } \\
\text { VEGF }\end{array}$} & Nonviscous \\
\hline & & Free flowing \\
\hline & & Readily drained \\
\hline & & Pleural fluid Cx negative \\
\hline \multirow{7}{*}{ Fibrinopurulent } & \multirow{7}{*}{$\begin{array}{l}\text { Fibrin deposition on } \\
\text { visceral pleura } \\
\text { Locules formation } \\
\text { IL-8, TNF- } \alpha\end{array}$} & $\mathrm{pH}>7.20$ \\
\hline & & $\begin{array}{l}\text { Glucose within normal } \\
\text { ranges }\end{array}$ \\
\hline & & LDH $<3$ times ULN \\
\hline & & Viscous \\
\hline & & More viscous \\
\hline & & Pleural fluid cx positive \\
\hline & & $\begin{array}{l}\text { Typical “complicated” } \\
\text { effusion }\end{array}$ \\
\hline \multirow{5}{*}{ Organizing } & \multirow{5}{*}{$\begin{array}{l}\text { Fibroblast entry } \\
\text { Pleural peel } \\
\text { TGF- } \beta\end{array}$} & Thick pus \\
\hline & & Very viscous \\
\hline & & $\mathrm{pH}<7.20$ \\
\hline & & Glucose $<40$ \\
\hline & & $\mathrm{LDH}>3$ times ULN \\
\hline
\end{tabular}

LDH: lactate dehydrogenase.

ULN: upper limits of normal.

VEGF: vascular endothelial growth factor.

IL-8: interleukin 8.

TNF- $\alpha$ : tumor necrosis factor-alpha.

TGF- $\beta$ : transforming growth factor-beta.

level is within the normal range and lactate dehydrogenase remains $<3$ times the upper limit of normal [12].

If the inflammation proceeds unabated, it leads to purulent and increasingly viscous pleural fluid, which is now rich in inflammatory cytokines like IL-1 and TNF$\alpha$. IL-1 induces mesothelial cells to release transforming growth factor (TGF- $\beta$ ) which is one of the most potent fibrogenic agents ever discovered [13]. This second stage called fibrinopurulent phase is characterized by positive microbial cultures and the effusion now is referred to as "complicated" (Figure 1). Patients with complicated parapneumonic effusions have higher pleural fluid levels of TNF$\alpha$, which is a marker of the degree of inflammation, than do patients with uncomplicated parapneumonic effusions
[14]. Pleural infection during this stage may respond to antibiotics and chest tube drainage but often requires invasive intervention. This is because of the continuing inflammation that there is a deposition of fibrin over the visceral pleura which in turn results in the formation of adhesions that impede lung re-expansion during attempts at fluid drainage. When the pleura is inflamed, the amount of fibrin that is laid down is the result of the balance between fibrinogenesis and fibrinolysis. Fibrogenesis occurs when the factors that favor fibrogenesis such as TNF- $\alpha$, TGF- $\beta$, and plasminogen activation inhibitor- 1 (PAI- 1 ) are dominant. Fibrinolysis occurs when more fibrin is being broken down than is being created [15]. If a fibrinopurulent effusion remains undrained, fibroblasts eventually deposit fibrotic tissue that encases the lung in inelastic peels [1618]. At this organizing phase, thick pleural peel restricts chest mechanics and often requires surgical decortications to address restrictive impairment.

\section{Bacteriology}

The bacteria isolated from infected pleural effusion vary significantly between community- and hospital-acquired infections. Maskell et al. conducted a large prospective MIST 1 trial (Multicenter Intrapleural Sepsis Trial 1) in 2005 [19]. In their study, 430 subjects were enrolled from 52 centres in the United Kingdom. Positive pleural cultures were found in $232(54 \%)$ of the subjects. The most common pathogen isolated was Streptococcus milleri group (29\%), followed by staphylococci (21\%) and Streptococcus pneumonia (16\%). Only $15 \%$ of effusions had anaerobes. Less common organisms responsible for community-acquired infection include other streptococci, enterobacteria, Haemophilus influenzae, Pseudomonas spp., tuberculosis, and Nocardia. In an earlier study [20], it was reported that nosocomial pleural infections were most commonly caused by methicillin-resistant Staphylococcus aureus (27\%), other staphylococci (22\%) and enterobacteria $(20 \%)$. Similar results were seen in a recent study of empyema in the intensive care unit setting by $\mathrm{Tu}$ et al. [21]. They found that Klebsiella pneumoniae was the most isolated microbe and also there was a high prevalence of polymicrobial infection. Even though the MIST 1 trial showed a low incidence of anaerobic organisms causing pleural infections, it is well known that they are difficult to isolate by culture of fluid and/or blood. Previous studies have shown that anaerobic bacteria were cultured in 36 


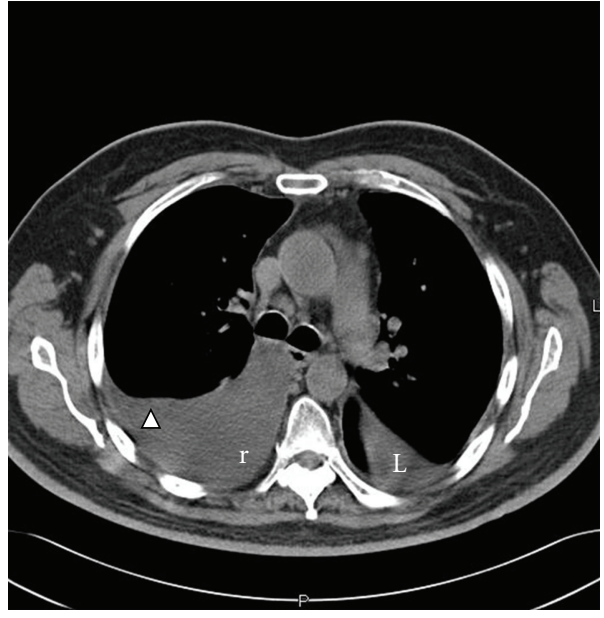

(a)

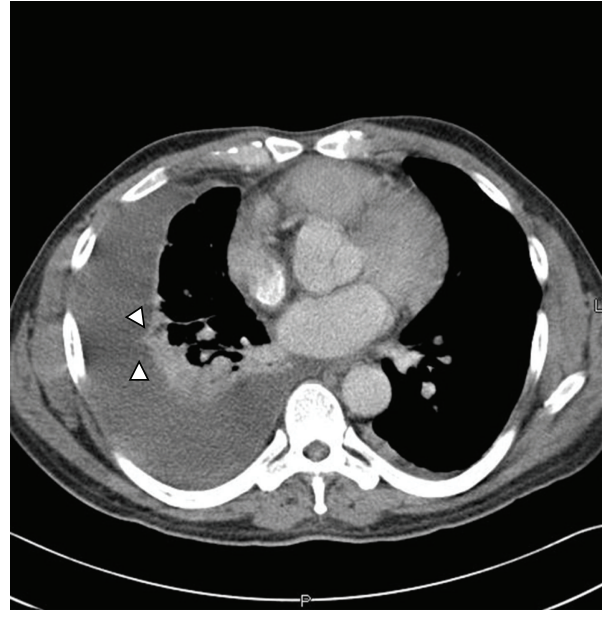

(b)

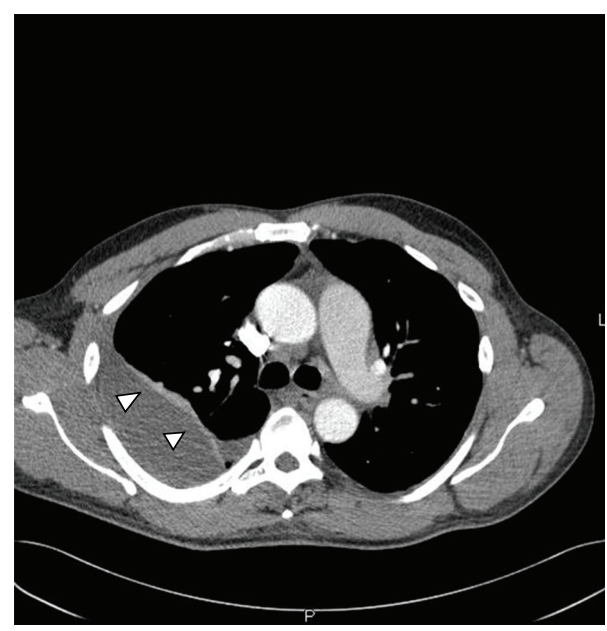

(c)

FIGURE 1: A series of CT images done in patient with parapneumonic effusions. (a) CT image showing a free flowing pleural effusion (r) with a meniscus formation (arrow). There is also some fluid in the fissure on the left side (L). (b) A loculated pleural effusion with loculations seen in the pleural space (arrows). (c) A chronic pleural effusion showing marked pleural thickening (arrows).

to 76 percent of human empyemas $[22,23]$ with predominant organisms isolated being Fusobacterium nucleatum, Prevotella sp, Peptostreptococcus, and the Bacteroides fragilis group although $\mathrm{B}$. fragilis is relatively rare [22, 24, 25].

\section{Therapeutic Approaches to Manage Pleural Infections}

There are very few randomized trials regarding management of pleural infections. This limits the evidence base to small observational reports and expert opinions leading to considerable variation in the treatment of individual patients. Depending on institutional expertise, the management of pleural infections can range from noninvasive treatment such as observation and antibiotic therapy to aggressive as well as invasive procedures like therapeutic aspiration, tube thoracostomy and intrapleural fibrinolytics, thoracoscopy, thoracotomy, or open drainage [12].
In recent times, application of these treatment modalities has been greatly aided by advanced imaging studies. With various imaging as well as treatment options at our disposal, there is a need for development of a multidisciplinary approach that can coordinate pulmonary, thoracic surgery, and interventional radiology expertise.

4.1. Antibiotics. Almost all patients with parapneumonic effusion will need antibiotic coverage. This coverage can be to treat the pneumonia or empirical coverage for a suspected pleural sepsis [1]. Even if the pleural fluid cultures are negative and there is a strong suspicion of pleural infection, clinician should initiate an empiric anaerobic coverage as an anaerobic infection will not grow well on culture media. According to the bacteriology listed for a communityacquired infection before the first choice will include intravenous amoxicillin with clavulanic acid or a combination of a second-generation cephalosporin (e.g., cefuroxime) and metronidazole or clindamycin if patient is penicillin allergic 
[26] patients with nosocomial empyema need adequate Gram-negative coverage, as Gram-negative infections are more common in nosocomial empyemas. Coverage should include at least a carbapenem or an antipseudomonal penicillin (e.g., piperacillin/tazobactam), or third- or fourthgeneration cephalosporins (e.g., ceftazidime, cefepime) with metronidazole. If there is a suspicion for MRSA, coinfection vancomycin or linezolid can be added. The single exception is that aminoglycosides may be inactivated at low pleural fluid $\mathrm{pH}$ [27].

4.2. Serial Thoracentesis. Therapeutic thoracentesis has been used for the treatment of parapneumonic effusions for almost two centuries [28]. In recent times, treating empyema or complicated parapneumonic effusions with serial therapeutic pleural aspirations has been largely abandoned. There have been no controlled studies comparing therapeutic thoracentesis with small-tube thoracostomy in the treatment of patients with complicated nonloculated parapneumonic effusions. Most of the recommendations are from some centers $[29,30]$ who advocate that patients should have daily therapeutic thoracentesis with or without pleural lavage in case of recurrence of infected effusions after initial thoracentesis to allow the pleural fluid to freely flow without any formation of locules until antibiotics resolve the infection. This approach may require an average of eight thoracentesis in $>2$ to 4 weeks. This was shown in a recent study done by Simmers et al. [31] in which they were able to successfully treat 24 of 29 patients with parapneumonic effusions by means of alternate-day ultrasound-guided pleural aspirations. This approach required that the patients undergo an average of $7.7 \pm 3.5$ thoracentesis with an average hospitalization of 31 days.

4.3. Chest Tube Drainage. Current indications for chest tube drainage are the aspiration of frankly purulent pleural fluid, the identification of organisms on pleural fluid Gram stain or culture, or a pleural fluid $\mathrm{pH}<7.2$ in the clinical setting of a pneumonic illness [32]. As an exception in a very large simple parapneumonic effusion, chest tube drainage may be done for symptomatic relief. According to old literature, chest tube drainage is most commonly achieved by a standard (24-28 french) intercostal chest drain, that is, positioned in the dependent part of a free-flowing pleural effusion (most often the posterior costophrenic recess). Using an imaging modality like ultrasound for inserting chest tube is advised as thickened parietal pleura, adhesions, or loculations often complicate insertion. Complete re-expansion of the lung, as demonstrated by repeat imaging, resolution of clinical and laboratory signs of infection, and avoidance of surgical drainage, defines successful drainage.

Till recent times, the common thinking was that smaller bore chest drains are likely to fail in the presence of pus with a high viscosity. However, some prospective studies [33-35] have found that 8- to 12 -french pigtail catheters or 10- to 14french catheters inserted with the Seldinger technique under US or CT guidance (Figure 2) were at least as effective as larger catheters inserted without imaging. Occlusion of the smaller drains can be avoided by the use of suction $(20 \mathrm{~cm}$ $\mathrm{H}_{2} \mathrm{O}$ ) and regular flushes (e.g., $30 \mathrm{~mL}$ normal saline every 6 hours). If the patient has not demonstrated significant improvement within $24 \mathrm{~h}$ of initiating tube thoracostomy, either the pleural drainage is unsatisfactory or the patient is receiving the wrong antibiotics. Unsatisfactory pleural drainage can be due to the tube being in the wrong location, loculation of the pleural fluid, or a fibrinous coating of the visceral pleura, which prevents the underlying lung from expanding. If drainage is inadequate, ultrasonography or a CT scan should be obtained to delineate which of the above factors is responsible. Data is still lacking to define the right time to remove the chest drain and thus general recommendations are to remove the drain when the daily output falls to less than $150 \mathrm{cc}$ for 2 consecutive days, in the setting of clinical and radiographic improvement.

The evidence base developing for small bore drains estimates a failure rate of $19 \%$ with their use in draining empyema [36]. A very recent study [35] of 71 complicated parapneumonic effusions and 70 empyemas drained with ultrasonographically guided small catheters showed a success rate of $80 \%(48 / 60)$ when the initial ultrasonography did not reveal significant loculations. In those patients with a complex septated pattern on ultrasonography, the success rate was still $51 \%(41 / 81)$. Authors concluded that the threshold for using fibrinolytics and large-bore catheters should be low in empyema.

Long-term indwelling catheters (Figure 3) are being increasingly used to drain malignant pleural effusions. Development of infection in the pleural space has been cited as a complication of this product. An article was published in 2008 [37] with two reports of use of indwelling catheters to treat pleural infection. The first case had a persistent bronchopleural fistula and the second case had esophageal rupture due to necrotizing TB lymphadenitis resulting in development of empyema in both cases. These cases suggested that small-bore indwelling catheters can have as successful outcomes as open drainage procedures and in addition provide patients with better quality of life during sustained pleural drainage. The current understanding is that during the early phase of pleural infection, short-term fine-bore pigtail catheter drainage can be useful, while for chronic pleural infection, long-term drainage can be effective without the problems of catheter blockage or tract infection. This approach needs validation with larger patient samples and randomized trials.

4.4. Intrapleural Fibrinolytics and DNase. Drainage of pleural fluid becomes challenging when there is formation of loculations inside the pleural cavity which resist drainage with a single chest tube. This has generated considerable interest in the use of intrapleural fibrinolytic agents and DNase (Table 3), which may facilitate fluid drainage by dissolving fibrinous adhesions. Development of dense layers of fibrin and loculations in a complicated parapneumonic effusions and empyemas are as a result of the procoagulant state within the pleural space as discussed in the pathophysiology of pleural infections. It, therefore, seems 


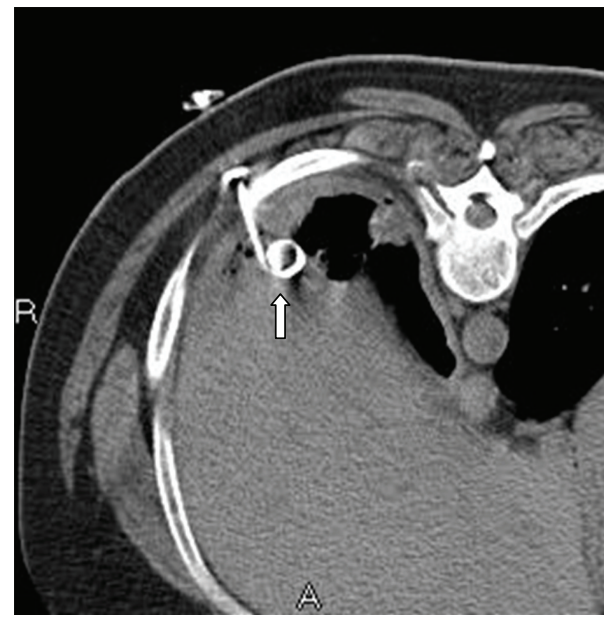

(a)

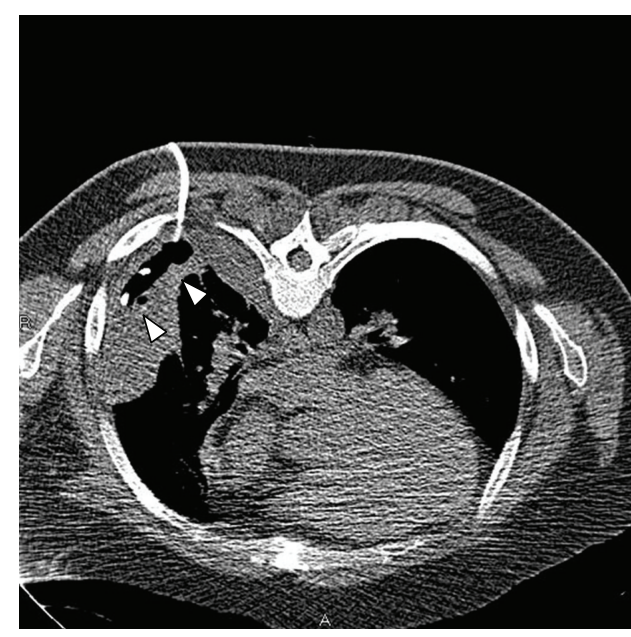

(b)

FIGURE 2: CT images after chest tube drainage. (a) Image shows placement of pigtail catheter (arrow) in the posterior recess confirmed with CT. (b) Placement of small-bore pigtail catheter (arrowheads) in the small loculated effusion with the help of CT guidance.

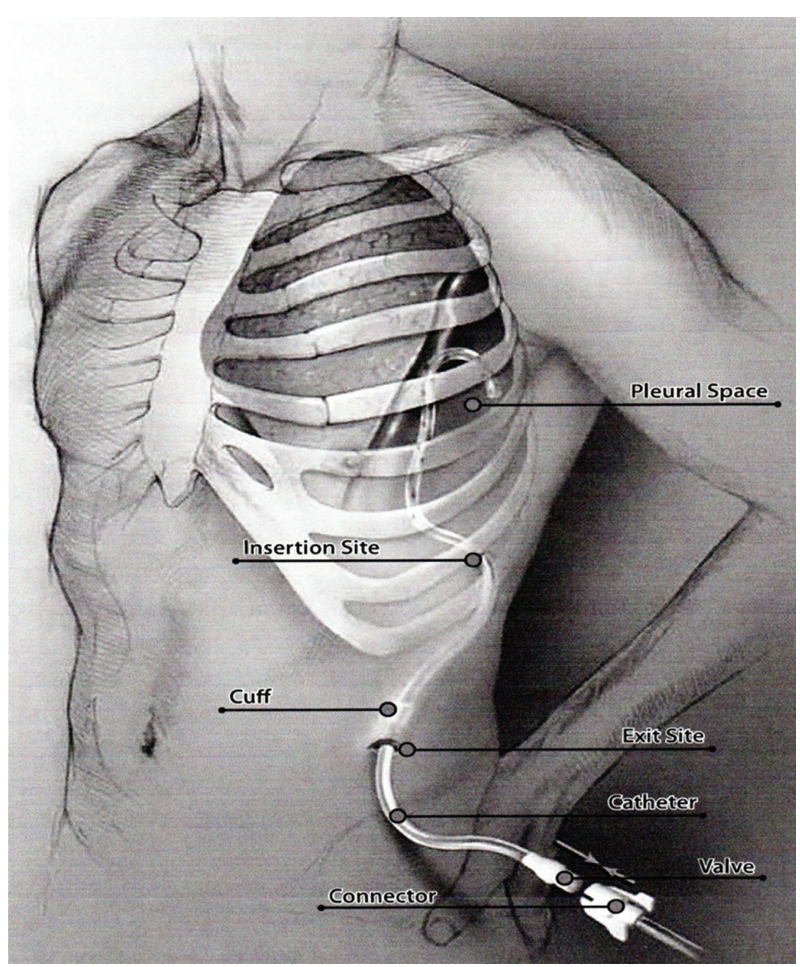

FIGURE 3: A pictorial representation of a chronic indwelling catheter (Aspira) which is tunneled beneath the skin to enter the pleural cavity at a distant site. This assembly prevents introduction of infection in the pleural cavity and can provide long term drainage of infected pleural effusion.

highly plausible that intrapleural fibrinolytics given early in the fibrinopurulent phase should prevent loculations and promote pleural drainage. Small studies [38-41] have reported the beneficial effects of therapy with streptokinase, urokinase, and rtPA for avoiding surgery and improving
TABle 3: Various intrapleural fibrinolytics (Adapted from Colice et al. [7]).

\begin{tabular}{lccc}
\hline Fibrinolytic & Dose & Instillation & Duration \\
\hline Streptokinase & $250,000 \mathrm{IU}$ & $100-200 \mathrm{cc}$ NS & QD for up to 7 days \\
Urokinase & $10,000 \mathrm{IU}$ & $100 \mathrm{cc} \mathrm{NS}$ & QD for up to 3 days \\
t-PA & $10-25 \mathrm{mg}$ & $100 \mathrm{cc} \mathrm{NS}$ & BID for up to 5 days \\
\hline
\end{tabular}

t-PA: tissue plasminogen activator.

IU: international units.

NS: normal saline.

QD: every day.

BID: twice a day.

the radiographic appearance of loculated effusions. Based on these early reports of efficacy from smaller studies, the BTS [26, 42] and the ACCP [7] (Table 1) guidelines have recommended fibrinolytic drugs as possible management options.

Till date, the largest randomized control trial of fibrinolytic therapy is the Multicenter Intrapleural Sepsis Trial (MIST1) done by Maskell et al. [19]. Study centers in this trial placed small-bore chest tubes (median size, 12F) without image guidance in 427 patients with complicated parapneumonic effusions (pleural fluid $\mathrm{pH}<7.20$, with signs of infection, or positive findings from a pleural fluid Gram stain or culture) or frank empyema and instilled streptokinase or placebo. The trial observed no benefits from streptokinase administration in terms of survival, decreased hospital stay, or need for surgery. However, there was a criticism about the methodology and implementation of this trial [43-45]. Patients did not undergo CT scanning or US imaging to identify locules or place chest tubes, and correct tube positioning was not confirmed after placement. There were concerns about the generalization of findings as no standardized protocols were used across the 52 centers to direct antibiotic or other treatments or to select patients who 


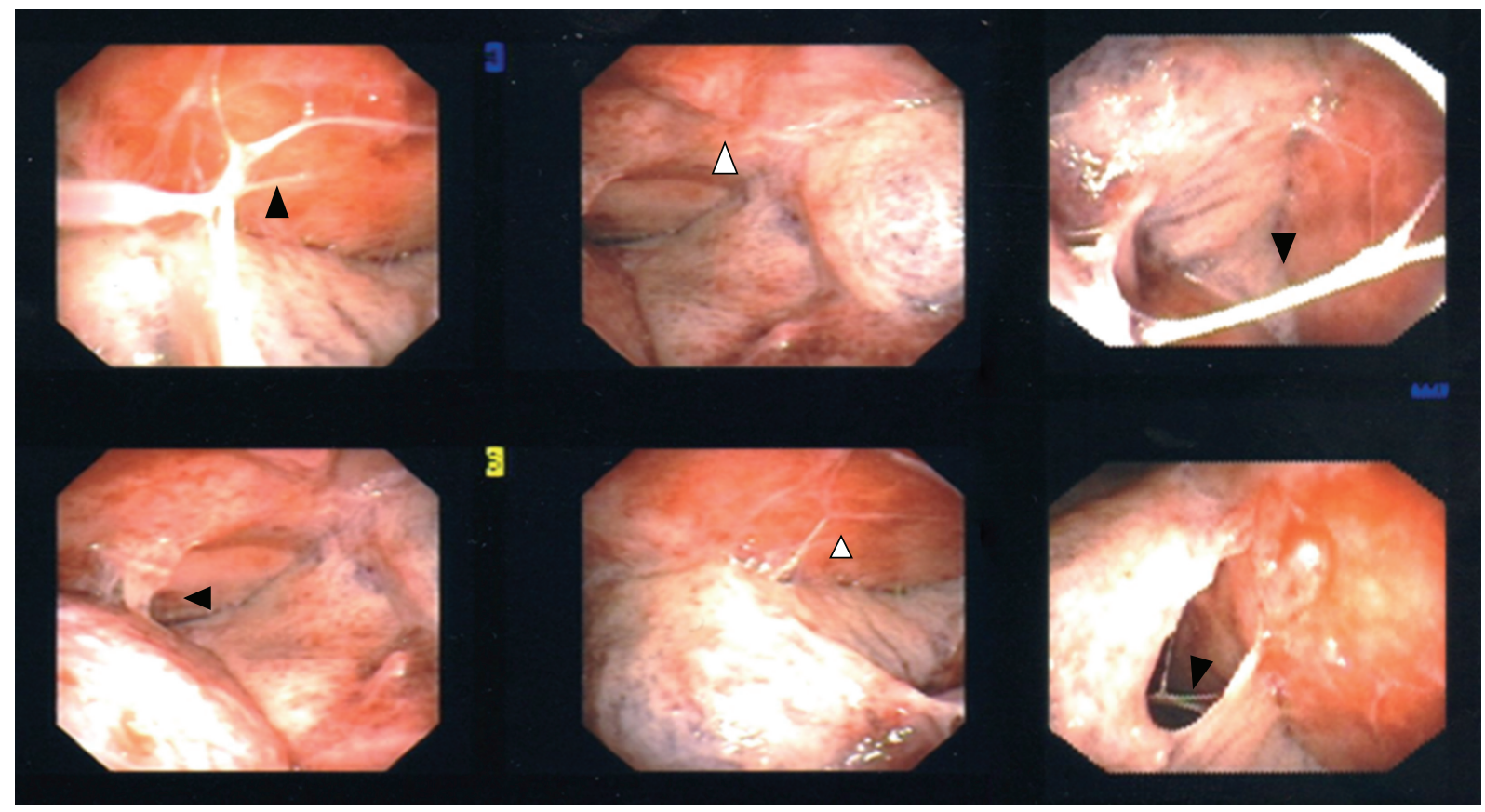

FIGURE 4: Thoracoscopic views of a complicated parapneumonic effusion. Multiple pleural adhesions (black arrowheads) are seen which prevent lungs from re-expanding. There are also seen inflamed pleura (white arrowheads) which represent nonresolving infection.

had not responded to fibrinolysis for surgery. Many of these centers lacked on-site surgical expertise and contributed only small numbers of patients. Even the drainage techniques were questioned as study design permitted small-bore chest tubes but did not report on pleural drainage volumes. Furthermore, streptokinase was mailed to study centers after randomization, which delayed fibrinolysis. Mortality as one of the endpoints was doubted as patients with serious concomitant illnesses that made survival beyond three months unlikely were excluded from the study. It was speculated that use of intrapleural streptokinase might yield better results in improving short-term mortality in a carefully selected patient population [43]. These deficiencies do not invalidate this large randomized trial, but concerns remain about the validity of its results with regards to younger, more severely ill patients and in different health care settings.

Streptokinase often loses effectiveness due to immunemediated neutralization; therefore, studies $[40,46,47]$ have been done using rtPA as the primary fibrinolytic. These studies estimate success rate of $86 \%$ with rtPA.

Similar results as in MIST1 were found in a metaanalysis [48] done subsequently to evaluate the benefit of fibrinolytic therapy in pleural sepsis. A Cochrane review [49] that included some studies $(n=761)$ also failed to show a reduction in death among patients who received fibrinolytic therapy (28 versus 33 percent). In view of conflicting results in different studies, currently there is not enough evidence to support routine fibrinolytic therapy for every patient with parapneumonic effusions.

Deoxyribose nucleoprotein content plays a major role in increasing the viscosity of pus in the pleural space.
Intrapleural fibrinolytics have negligible effects on decreasing the viscosity of empyema pus in contrast to agents that depolymerize DNA, such as human recombinant deoxyribonuclease. Benefit of intrapleural human recombinant DNase in the treatment of empyema following failure of streptokinase has been reported only in case reports [50]. In a recent UK trial comparing the effects of intrapleural tPA, intrapleural fibrinolytics and both combined with placebo showed insignificant response in pleural infection resolution with tPA or DNase alone. On the other hand, the combination of tPA-DNase instilled in the intrapleural space improved fluid drainage and reduced the frequency of surgical referral and the duration of the hospital stay [51]. These initial case reports and trial hint toward a potential new therapy which can improve outcomes of semi-invasive therapies.

4.5. Thoracoscopy. Thoracoscopy is a technique which is able to provide a minimally invasive access to the pleural space to suction viscous pleural fluid, lyse adhesion in loculated pleural effusions, and place chest tubes in dependent regions of pleural fluid under direct visualization [12]. Loculations can be broken down, the visible pleural space completely drained, and an intercostal chest tube can be optimally placed [12]. Thoracoscopy in comparison to thoracostomy has the advantage of having less postoperative pain, lower costs, shorter hospital stays, and better cosmetic results [52]. Available thoracoscopic procedures include medical thoracoscopy and video-assisted thoracoscopic surgery (VATS).

Medical thoracoscopy (Figure 4) has been shown to provide resolution of tuberculous pleural effusions by 


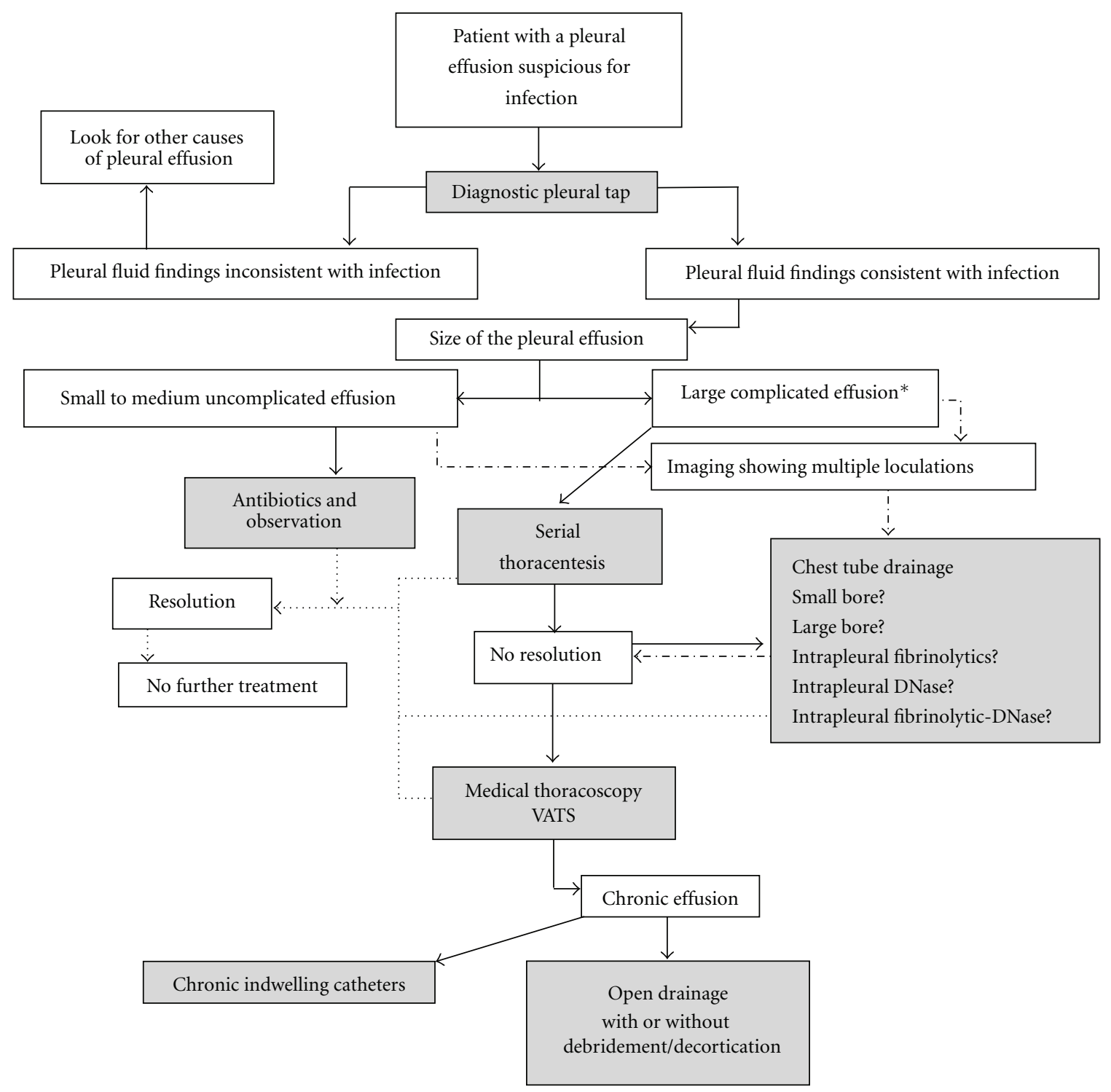

FIGURE 5: A schematic flow chart summarizing the various treatment modalities available for managing pleural infection and various stages where each of them may be used. Decisions regarding timing of each treatment option may vary according to institutional expertise. * Empyema or effusions with either gram stain or culture positive, $\mathrm{pH}<7.2$, glucose $<60 \mathrm{mg} / \mathrm{dL}, \mathrm{LDH}<1000$.

repeated adhesionolysis since early part of 20th century in Europe $[53,54]$. Medical thoracoscopy is a cheap and quick procedure which can easily be done in an endoscopy suit with patient under conscious sedation and breathing spontaneously within 30-60 minutes [55]. Medical thoracoscopy is performed via single chest port in contrast to VATS, and does not require complete collapse of the lung. Limitation of medical thoracoscopy lies in its inability to fully examine the pleural cavity and to perform pleurectomy if needed. Additionally, debridement done using medical thoracoscopy is time consuming and cumbersome.

Again, there has been a lack of large randomized controlled trial for establishing the role of medical thoracoscopy. A recent case series [56] which analyzed the benefit of medical thoracoscopy for treatment of ultrasonographically stratified multiloculated pleural effusion showed a primary success rate of $91 \%$. Taking in account patients who required additional chest tube insertion or second medical thoracoscopy procedure, the success rates further improved to $94 \% .6 \%$ of cases required conversion to open drainage. This case series reported the use of intrapleural fibrinolytics as an adjunctive therapy after the thoracoscopy procedure in $49 \%$ of cases. Complications occurred in $9 \%$ of patients with no mortality observed due to the procedure itself.

VATS is a procedure which is performed by a cardiothoracic surgeon generally using a three-entry port and a double-lumen endotracheal tube. Using VATS, surgeons can also perform decortication and pleurectomy if needed. Even though VATS in comparison to medical thoracoscopy can provide the operator with a much larger access to the pleural 
space, it may still prove out to be inadequate to treat thick empyemas complicated by dense adhesions and multiple loculations. Studies on VATS procedure have reported a success rate of $60-100 \%$. Currently, VATS is reserved for treating complicated fibrinopurulent effusions, with some surgeons using it during the organizing phase and then converting to thoracostomy if it fails [57-60].

4.6. Open Drainage. An open drainage procedure is employed when the minimally invasive procedures fail to achieve acceptable resolution, defined as re-expansion of lung to the chest wall. In the early exudative or fibrinopurulent stages, an open drainage procedure helps to control the pleural sepsis while the main aim in an organizing phase is to remove the fibrotic peel that encases the lung in order to help it to re-expand and improve chest dynamics $[12,61,62]$.

Open drainage is achieved using two types of approaches. First being thoracotomy with drainage and subsequent closure of the chest with one or more drains left in the pleural cavity. Second approach involves creating a window in the pleural cavity by chest wall incision and rib resection, which provides continuous drainage of the chest cavity. This is called thoracostomy. Through the window in the chest wall drainage can be facilitated by inserting chest tubes. After complete removal of the empyema, chest tubes can be withdrawn. Thoracotomy procedure can also help in complete or partial decortication of the pleural membranes coated with fibrous tissue which will in turn expedite evacuation of thick pus in the pleural cavity and let the lung reexpand [63]. Debridement in comparison to decortication which is a major thoracic operation is less aggressive and can be better tolerated by patients who are markedly debilitated [64].

In a review of 25 patients [65] who underwent either decortication or debridement for empyema drainage, the outcomes were studied by measuring the change of the pleural cavity size before, immediately after surgery, and on followup. On followup imaging, the eventual size of the pleural cavity was not different between the two procedure groups $(P<0.937)$. Thus, almost similar results were achieved by debridement alone without decortication in patients presenting with empyema, despite the presence of an underlying trapped lung.

\section{Conclusions}

The management principles for pleural infection have come a long way from employing antibiotic therapy and thoracentesis to the current availability of semi-invasive and invasive procedures. The key to successful management of pleural infection still remains to be early diagnosis and initiation of treatment. Due to the paucity of robust clinical trials, the treatment modality or the management approach chosen largely depends on individual and institutional expertise. Clinicians are encouraged to develop standardized protocols using best practices reported in the literature, for early identification and management (Figure 5).
Use of advanced imaging like ultrasound and CT scans widens the scope of diagnosing and treating effusions seen on a routine postero-anterior chest radiograph. Observation is usually adequate for a small $(<10 \mathrm{~mm})$ unseptated, free flowing effusions. Any other effusions warrant a diagnostic thoracentesis. If the aspirated fluid fulfills the criteria for being infected $(\mathrm{pH}<7.2$, glucose $<40 \mathrm{mg} / \mathrm{dL}$, culture positive), a prompt plan for its drainage is needed. Currently, large bore tube thoracostomy is the treatment option of choice for patients with empyema, but data is accumulating for treating parapneumonic effusions with small-bore intercostal drains.

The use of fibrinolytics still remains controversial. Fibrinolytics will have more defined role for treating loculated parapneumonic effusions and empyema, particularly in young, acutely ill patients, poor surgical candidates, and in centres with inadequate surgical facilities. Early thoracoscopy is an alternative to thrombolytics. Local expertise will dictate the choice between therapeutic thoracentesis, intrapleural fibrinolytics, and medical thoracoscopy as well as conversion to open drainage when thoracoscopy fails till randomized trials provide with better evidence.

\section{References}

[1] S. J. Chapman and R. J. O. Davies, "Recent advances in parapneumonic effusion and empyema," Current Opinion in Pulmonary Medicine, vol. 10, no. 4, pp. 299-304, 2004.

[2] S. A. Sahn, "Management of complicated parapneumonic effusions," American Review of Respiratory Disease, vol. 148, no. 3, pp. 813-817, 1993.

[3] C. W. H. Davies, S. E. Kearney, F. V. Gleeson, and R. J. O. Davies, "Predictors of outcome and long-term survival in patients with pleural infection," American Journal of Respiratory and Critical Care Medicine, vol. 160, no. 5 I, pp. 16821687, 1999.

[4] A. K. Mandal, H. Thadepalli, A. K. Mandal, and U. Chettipally, "Outcome of primary empyema thoracis: therapeutic and microbiologic aspects," Annals of Thoracic Surgery, vol. 66, no. 5, pp. 1782-1786, 1998.

[5] F. Farjah, R. G. Symons, B. Krishnadasan, D. E. Wood, and D. R. Flum, "Management of pleural space infections: a population-based analysis," Journal of Thoracic and Cardiovascular Surgery, vol. 133, no. 2, pp. 346-351, 2007.

[6] C. Finley, J. Clifton, J. M. FitzGerald, and J. Yee, "Empyema: an increasing concern in Canada," Canadian Respiratory Journal, vol. 15 , no. 2 , pp. 85-89, 2008.

[7] G. L. Colice, A. Curtis, J. Deslauriers et al., "Medical and surgical treatment of parapneumonic effusions: an evidencebased guideline," Chest, vol. 118, no. 4, pp. 1158-1171, 2000.

[8] J. E. Heffner, J. McDonald, C. Barbieri, and J. Klein, "Management of parapneumonic effusions: an analysis of physician practice patterns," Archives of Surgery, vol. 130, no. 4, pp. 433438, 1995.

[9] M. W. A. Chu, L. R. S. Dewar, J. J. Burgess, and E. G. F. Busse, "Empyema thoracis: lack of awareness results in a prolonged clinical course," Canadian Journal of Surgery, vol. 44, no. 4, pp. 284-288, 2001.

[10] N. C. Andrews, E. F. Parker, R. R. Shaw et al., "Management of nontruberculous empyema," American Review of Respiratory Disease, vol. 85, pp. 935-936, 1962. 
[11] C. S. Grove and Y. C. G. Lee, "Vascular endothelial growth factor: the key mediator in pleural effusion formation," Current Opinion in Pulmonary Medicine, vol. 8, no. 4, pp. 294-301, 2002.

[12] R. W. Light, "Parapneumonic effusions and empyema," Proceedings of the American Thoracic Society, vol. 3, no. 1, pp. 7580, 2006.

[13] C. L. Chung, C. H. Chen, J. R. Sheu, Y. C. Chen, and S. C. Chang, "Proinflammatory cytokines, transforming growth factor- $\beta 1$, and fibrinolytic enzymes in loculated and freeflowing pleural exudates," Chest, vol. 128, no. 2, pp. 690-697, 2005.

[14] M. G. Alexandrakis, S. A. Coulocheri, D. Bouros, and G. D. Eliopoulos, "Evaluation of ferritin, interleukin-6, interleukin8 and tumor necrosis factor alpha in the differentiation of exudates and transudates in pleural effusions," Anticancer Research, vol. 19, no. 4 C, pp. 3607-3612, 1999.

[15] S. Idell, C. Zwieb, A. Kumar, K. B. Koenig, and A. R. Johnson, "Pathways of fibrin turnover of human pleural mesothelial cells in vitro," American Journal of Respiratory Cell and Molecular Biology, vol. 7, no. 4, pp. 414-426, 1992.

[16] S. Idell, W. Girard, K. B. Koenig, J. McLarty, and D. S. Fair, "Abnormalities of pathways of fibrin turnover in the human pleural space," American Review of Respiratory Disease, vol. 144, no. 1, pp. 187-194, 1991.

[17] C. Alemán, J. Alegre, J. Monasterio et al., “Association between inflammatory mediators and the fibrinolysis system in infectious pleural effusions," Clinical Science, vol. 105, no. 5, pp. 601-607, 2003.

[18] S. A. Sasse, M. R. Jadus, and G. D. Kukes, "Pleural fluid transforming growth factor- $\beta_{1}$ correlates with pleural fibrosis in experimental empyema," American Journal of Respiratory and Critical Care Medicine, vol. 168, no. 6 I, pp. 700-705, 2003.

[19] N. A. Maskell, C. W. H. Davies, A. J. Nunn et al., "U.K. controlled trial of intrapleural streptokinase for pleural infection," New England Journal of Medicine, vol. 352, no. 9, pp. 865-874, 2005.

[20] N. A. Maskell, C. W. Davies, E. Jones, and R. J. O. Davies, "The characteristics of 300 patients participating in the MRC/BTS multicenter intra-pleural streptokinase vs. placebo trial (ISRCTN-39138989)," in Proceedings of the American Thoracic Society Meeting, Atlanta, Ga, USA, 2002.

[21] C. Y. Tu, W. H. Hsu, T. C. Hsia et al., "The changing pathogens of complicated parapneumonic effusions or empyemas in a medical intensive care unit," Intensive Care Medicine, vol. 32, no. 4, pp. 570-576, 2006.

[22] I. Brook and E. H. Frazier, "Aerobic and anaerobic microbiology of empyema: a retrospective review in two military hospitals," Chest, vol. 103, no. 5, pp. 1502-1507, 1993.

[23] J. G. Bartlett, S. L. Gorbach, H. Thadepalli, and S. M. Finegold, "Bacteriology of empyema," The Lancet, vol. 1, no. 7853, pp. 338-340, 1974.

[24] R. Civen, H. Jousimies-Somer, M. Marina, L. Borenstein, H. Shah, and S. M. Finegold, "A retrospective review of cases of anaerobic empyema and update of bacteriology," Clinical Infectious Diseases, vol. 20, supplement 2, pp. S224-S229, 1995.

[25] L. Boyanova, G. Gergova, D. Iotov et al., "Anaerobic microbiology in 198 cases of pleural empyema: a Bulgarian study," Anaerobe, vol. 10, no. 5, pp. 261-267, 2004.

[26] C. W. H. Davies, F. V. Gleeson, and R. J. O. Davies, "BTS Pleural Disease Group, a sub-group of the BTS Standards of
Care Committee: BTS guidelines for the management of pleural infection," Thorax, vol. 58, supplement 2, pp. ii18-ii28, 2003.

[27] P. Vaudaux and F. A. Waldvogel, "Gentamicin inactivation in purulent exudates: role of cell lysis," Journal of Infectious Diseases, vol. 142, no. 4, pp. 586-593, 1980.

[28] H. I. Bowditch, "Paracentesis thoracic: an analysis of 25 cases of pleuritic effusion," American Medical Monthly, pp. 3-45, 1853.

[29] H. K. Ryaa Storm, M. Krasnik, K. Bang, and N. FrimodtMoller, "Treatment of pleural empyema secondary to pneumonia: thoracocentesis regimen versus tube drainage," Thorax, vol. 47, no. 10, pp. 821-824, 1992.

[30] S. Sasse, T. Nguyen, L. R. Teixeira, and R. W. Light, “The utility of daily therapeutic thoracentesis for the treatment of early empyema," Chest, vol. 116, no. 6, pp. 1703-1708, 1999.

[31] T. A. Simmers, C. Jie, and B. Sie, "Minimally invasive treatment of thoracic empyema," Thoracic and Cardiovascular Surgeon, vol. 47, no. 2, pp. 77-81, 1999.

[32] J. E. Heffner, L. K. Brown, C. Barbieri, and J. M. DeLeo, "Pleural fluid chemical analysis in parapneumonic effusions: a meta-analysis," American Journal of Respiratory and Critical Care Medicine, vol. 151, no. 6, pp. 1700-1708, 1995.

[33] S. Shankar, M. Gulati, M. Kang, S. Gupta, and S. Suri, "Imageguided percutaneous drainage of thoracic empyema: can sonography predict the outcome?" European Radiology, vol. 10, no. 3, pp. 495-499, 2000.

[34] I. Ali and H. Unruh, "Management of empyema thoracis," Annals of Thoracic Surgery, vol. 50, no. 3, pp. 355-359, 1990.

[35] D. G. Ashbaugh, "Empyema thoracis: factors influencing morbidity and mortality," Chest, vol. 99, no. 5, pp. 1162-1165, 1991.

[36] A. N. Keeling, S. Leong, P. M. Logan, and M. J. Lee, "Empyema and effusion: outcome of image-guided small-bore catheter drainage," CardioVascular and Interventional Radiology, vol. 31, no. 1, pp. 135-141, 2008.

[37] H. E. Davies, N. M. Rahman, R. J. Parker, and R. J. O. Davies, "Use of indwelling pleural catheters for chronic pleural infection," Chest, vol. 133, no. 2, pp. 546-549, 2008.

[38] A. H. Diacon, J. Theron, M. M. Schuurmans, B. W. Van De Wal, and C. T. Bolliger, "Intrapleural streptokinase for empyema and complicated parapneumonic effusions," American Journal of Respiratory and Critical Care Medicine, vol. 170, no. 1, pp. 49-53, 2004.

[39] D. Bouros, S. Schiza, N. Tzanakis, G. Chalkiadakis, J. Drositis, and N. Siafakas, "Intrapleural urokinase versus normal saline in the treatment of complicated parapneumonic effusions and empyema: a randomized, double-blind study," American Journal of Respiratory and Critical Care Medicine, vol. 159, no. 1, pp. 37-42, 1999.

[40] D. A. Gervais, D. A. Levis, P. F. Hahn, R. N. Uppot, R. S. Arellano, and P. R. Mueller, "Adjunctive intrapleural tissue plasminogen activator administered via chest tubes placed with imaging guidance: effectiveness and risk for hemorrhage," Radiology, vol. 246, no. 3, pp. 956-963, 2008.

[41] R. J. O. Davies, Z. C. Traill, and F. V. Gleeson, "Randomised controlled trial of intrapleural streptokinase in community acquired pleural infection," Thorax, vol. 52, no. 5, pp. 461-421, 1997.

[42] I. M. Balfour-Lynn, E. Abrahamson, G. Cohen et al., "BTS guidelines for the management of pleural infection in children," Thorax, vol. 60, no. 1, pp. i1-i21, 2005. 
[43] J. E. Heffner, "Multicenter trials of treatment for empyemaafter all these years," New England Journal of Medicine, vol. 352, no. 9, pp. 926-928, 2005.

[44] A. H. Diacon, C. F. N. Koegelenberg, C. T. Bolliger et al., "A trial of intrapleural streptokinase," New England Journal of Medicine, vol. 352, no. 21, pp. 2243-2245, 2005.

[45] D. Bouros, K. M. Antoniou, and R. W. Light, "Intrapleural streptokinase for pleural infection," British Medical Journal, vol. 332, no. 7534, pp. 133-134, 2006.

[46] C. A. Walker, M. B. Shirk, M. M. Tschampel, J. A. Visconti, B. R. Morand, and C. Guévremont, "Intrapleural alteplase in a patient with complicated pleural effusion," Annals of Pharmacotherapy, vol. 37, no. 3, pp. 376-379, 2003.

[47] D. A. Skeete, E. J. Rutherford, S. A. Schlidt, J. E. Abrams, L. A. Parker, and P. B. Rich, "Intrapleural tissue plasminogen activator for complicated pleural effusions," Journal of Trauma, vol. 57, no. 6, pp. 1178-1183, 2004.

[48] Y. Tokuda, D. Matsushima, G. H. Stein, and S. Miyagi, "Intrapleural fibrinolytic agents for empyema and complicated parapneumonic effusions: a meta-analysis," Chest, vol. 129, no. 3, pp. 783-790, 2006.

[49] R. Cameron and H. R. Davies, "Intra-pleural fibrinolytic therapy versus conservative management in the treatment of adult parapneumonic effusions and empyema," Cochrane Database of Systematic Reviews, no. 2, article CD002312, 2008.

[50] G. Simpson, D. Roomes, and M. Heron, "Effects of streptokinase and deoxyribonuclease on viscosity of human surgical and empyema pus," Chest, vol. 117, no. 6, pp. 1728-1733, 2000.

[51] N. M. Rahman, N. A. Maskell, A. West et al., "Intrapleural use of tissue plasminogen activator and DNase in pleural infection," New England Journal of Medicine, vol. 365, no. 6, pp. 518-526, 2011.

[52] J. R. Roberts, D. S. Weiman, D. L. Miller, A. Y. Afifi, and R. R. Kraeger, "Minimally invasive surgery in the treatment of empyema: intraoperative decision making," Annals of Thoracic Surgery, vol. 76, no. 1, pp. 225-230, 2003.

[53] J. M. Tschopp, C. Boutin, P. Astoul et al., "Talcage by medical thoracoscopy for primary spontaneous pneumothorax is more cost-effective than drainage: a randomised study," European Respiratory Journal, vol. 20, no. 4, pp. 1003-1009, 2002.

[54] J. M. Tschopp, M. Brutsche, and J. G. Frey, "Treatment of complicated spontaneous pneumothorax by simple talc pleurodesis under thoracoscopy and local anaesthesia," Thorax, vol. 52, no. 4, pp. 329-332, 1997.

[55] R. Loddenkemper, "Thoracoscopy-state of the art," European Respiratory Journal, vol. 11, no. 1, pp. 213-221, 1998.

[56] M. H. Brutsche, G. F. Tassi, S. Györik et al., "Treatment of sonographically stratified multiloculated thoracic empyema by medical thoracoscopy," Chest, vol. 128 , no. 5, pp. 3303 3309, 2005.

[57] G. F. Tassi, R. J. O. Davies, and M. Noppen, "Advanced techniques in medical thoracoscopy," European Respiratory Journal, vol. 28, no. 5, pp. 1051-1059, 2006.

[58] A. J. Drain, J. I. Ferguson, R. Sayeed, S. Wilkinson, and A. Ritchie, "Definitive management of advanced empyema by two-window video-assisted surgery," Asian Cardiovascular and Thoracic Annals, vol. 15, no. 3, pp. 238-239, 2007.

[59] D. A. Waller, "Thoracoscopy in management of postpneumonic pleural infections," Current Opinion in Pulmonary Medicine, vol. 8, no. 4, pp. 323-326, 2002.

[60] P. C. Cassina, M. Hauser, L. Hillejan, D. Greschuchna, G. Stamatis, and J. Deslauriers, "Video-assisted thoracoscopy in the treatment of pleural empyema: stage-based management and outcome," Journal of Thoracic and Cardiovascular Surgery, vol. 117, no. 2, pp. 234-238, 1999.

[61] S. A. Sasse, "Parapneumonic effusions and empyema," Current Opinion in Pulmonary Medicine, vol. 2, no. 4, pp. 320-326, 1996.

[62] R. J. Thurer, "Decortication in thoracic empyema: indications and surgical technique," Chest Surgery Clinics of North America, vol. 6, no. 3, pp. 461-490, 1996.

[63] A. K. Mandal, H. Thadepalli, A. K. Mandal, and U. Chettipally, "Outcome of primary empyema thoracis: therapeutic and microbiologic aspects," Annals of Thoracic Surgery, vol. 66, no. 5, pp. 1782-1786, 1998.

[64] V. Pothula and D. J. Krellenstein, "Early aggressive surgical management of parapneumonic empyemas," Chest, vol. 105, no. 3, pp. 832-836, 1994.

[65] T. A. A. Mackinlay, G. A. Lyons, D. J. Chimondeguy, M. A. Barboza Piedras, G. Angaramo, and J. Emery, "VATS debridement versus thoracotomy in the treatment of loculated postpneumonia empyema," Annals of Thoracic Surgery, vol. 61, no. 6, pp. 1626-1630, 1996. 


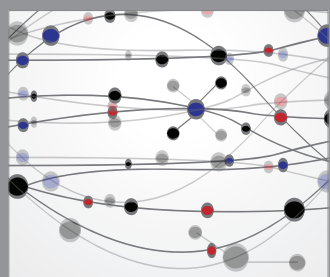

The Scientific World Journal
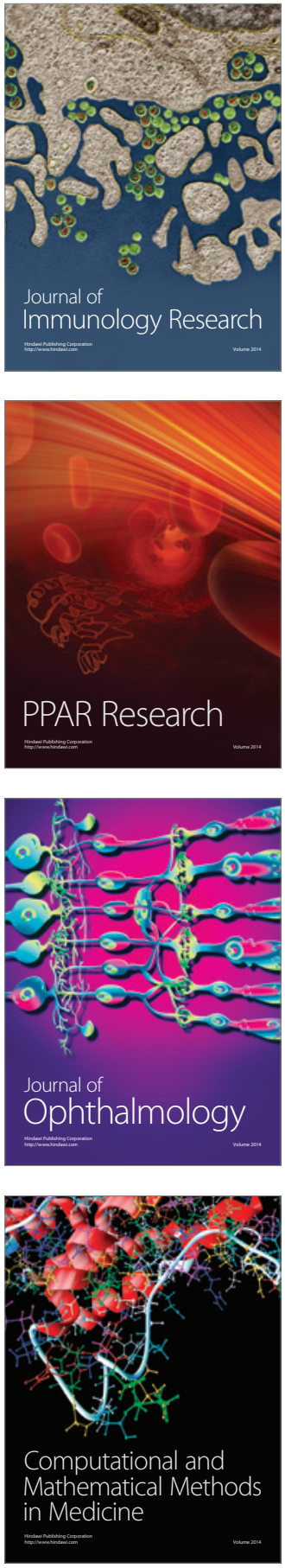

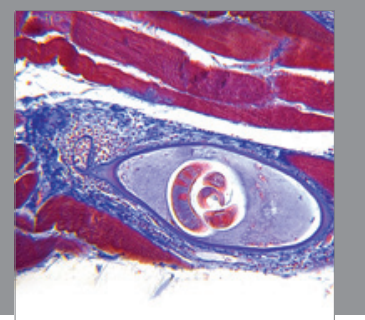

Gastroenterology

Research and Practice
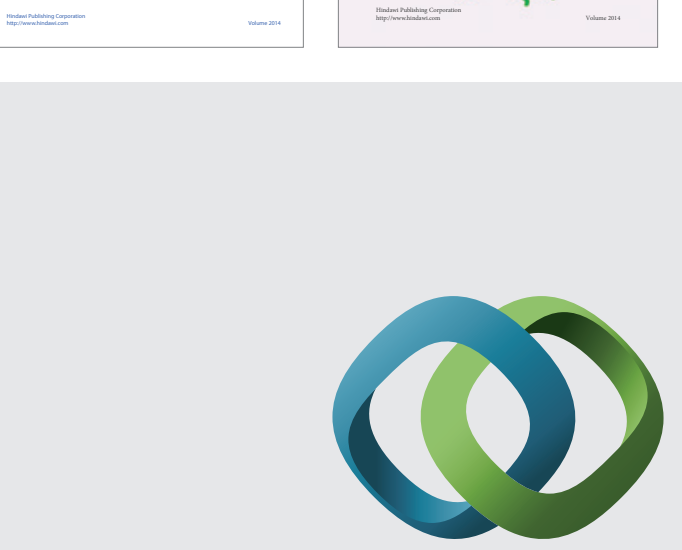

\section{Hindawi}

Submit your manuscripts at

http://www.hindawi.com
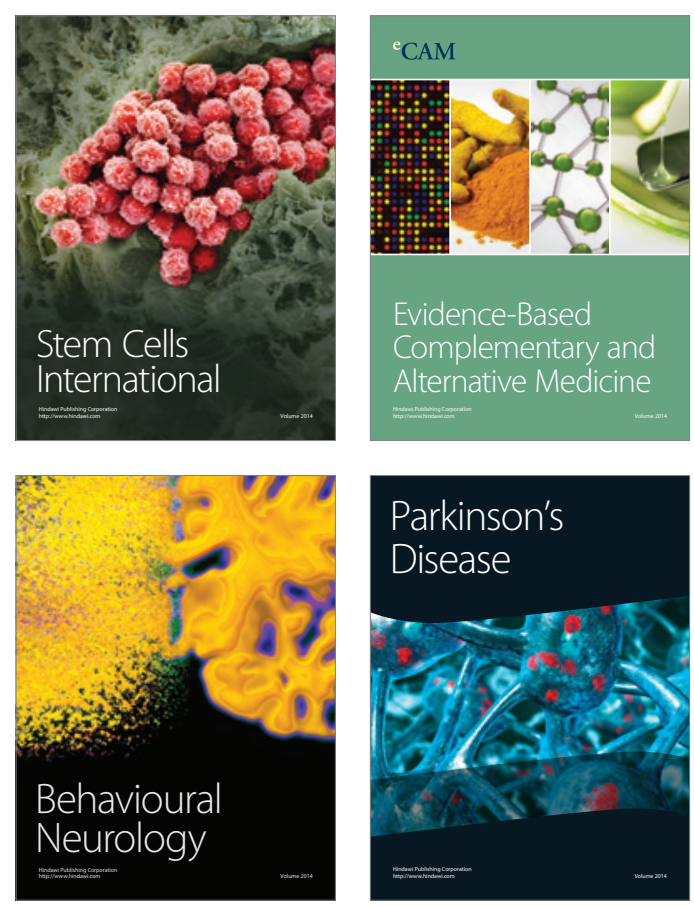

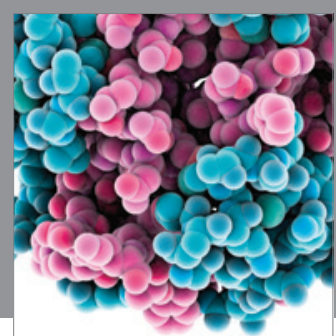

Journal of
Diabetes Research

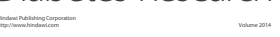

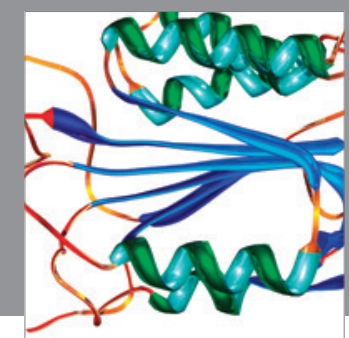

Disease Markers
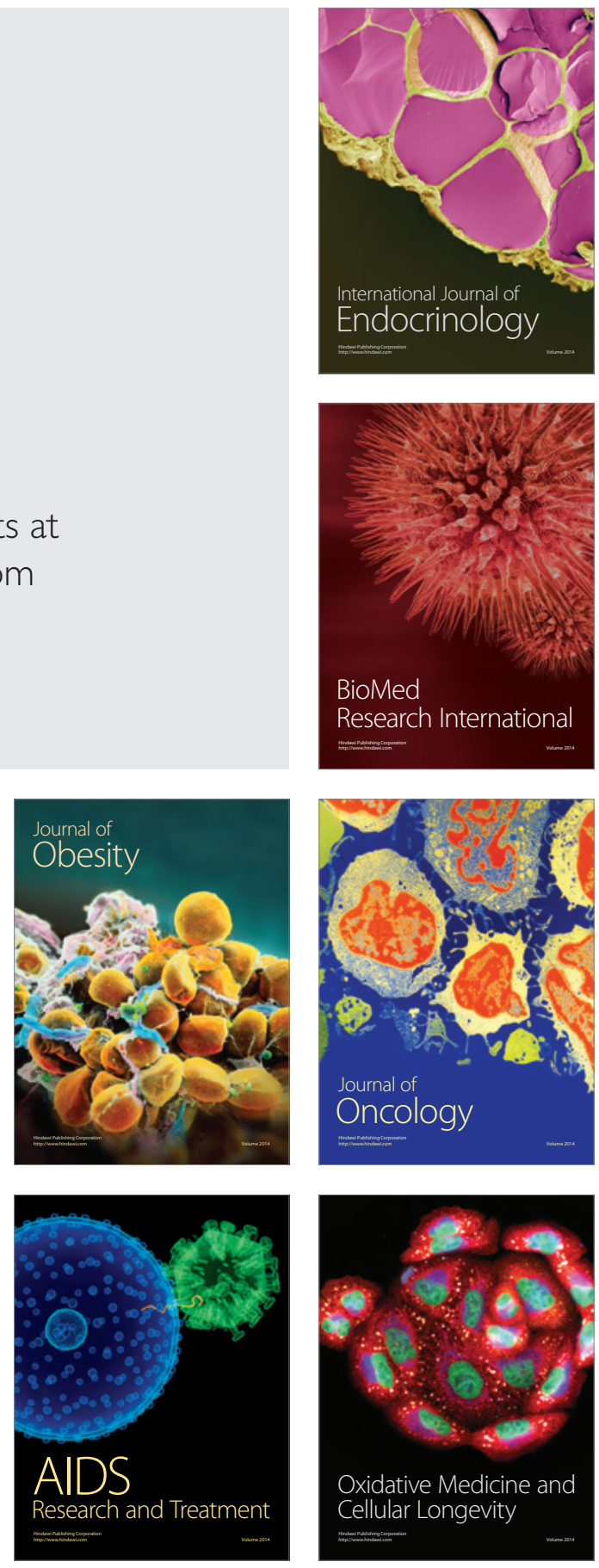